\title{
ORIGEN DE LA NOCIÓN DE SERVICIO PÚBLICO EN EL DERECHO FRANCÉS Y SU RECEPCIÓN EN EL DERECHO ESPAÑOL. UN ENFOQUE CRÍTICO
}

\author{
FLAVIO QUEZADA RODRÍGUEZ' \\ Universidad de Barcelona
}

\author{
Cómo citar/Citation \\ Quezada Rodríguez, F. (2021). \\ Origen de la noción de servicio público en el derecho \\ francés y su recepción en el derecho español. Un enfoque crítico. \\ Revista de Administración Pública, 216, 141-168. \\ doi: https://doi.org/10.18042/cepc/rap.216.05
}

\section{Resumen}

La noción de servicio público sigue siendo un tema clave para comprender el derecho administrativo francés y español, así como sus relaciones y vínculos. Este estudio se propone revisitar este tema, desde el administrativismo crítico y el comparatismo crítico, en una reflexión en tres tiempos: primero, se reconstruye la elaboración de la noción francesa de servicio público; en un segundo momento, se desarrollan los vínculos entre dicho proceso con la construcción propiamente espańola; y, finalmente, se entregan algunas conclusiones que se siguen de lo anterior y que podrían dar lugar a investigaciones futuras.

\section{Palabras claves}

Noción de servicio público; comparación jurídica; historia del derecho administrativo; derecho administrativo crítico.

\footnotetext{
1 Esta investigación se desarrolló gracias al financiamiento de la Agencia Nacional de Investigación y Desarrollo de la República de Chile (CONICYT PFCHA/DOCTORADO BECAS CHILE/2018 - 72190220).
} 


\section{Abstract}

The notion of public service remains a crucial issue for understanding French and Spanish administrative law, as well as their relations. This study sets out to revisit this subject, from the perspective of critical administrative and comparative law, in a three-stage reflection: first, it reconstructs the development of the French notion of public service; second, it develops the links between this process and the Spanish theoretical development; finally, it offers some conclusions that follow from the study, and that could give rise to future research.

\section{Keywords}

Public service; legal comparison; history of administrative law; critical administrative law. 


\section{SUMARIO}

I. INTRODUCCIÓN. II. LA FORMACIÓN DE LA NOCIÓN FRANCESA DE SERVICIO PÚBLICO: 1. La génesis y genealogía de una polisémica noción propiamente francesa. 2. La mitificación de la decisión Blanco de 1873. III. UNA CREATIVA «RECEPCIÓN» EN EL DERECHO ESPAÑOL: 1. Terreno fértil para la recepción: una larga influencia francesa y la construcción de una noción de servicio público en Posada. 2. La noción de servicio público «en sentido estricto» como una creación propiamente Española. IV. CONCLUSIONES.

\section{INTRODUCCIÓN}

No puede pensarse el derecho sin nociones o $\operatorname{conceptos}^{2}$, aunque «están abocados a mutar en el transcurso del tiempo» ${ }^{3}$. Para ser capaz de percibir y explicar sus mutaciones se requiere una genuina apertura epistemológica ${ }^{4}$ hacia un pluralismo metodológico ${ }^{5}$, puesto que «el derecho administrativo es íntegramente un componente de la realidad política, doblemente arraigado, en el tiempo y el espacio. Como elemento de una totalidad que le comunica su lógica, registra los diversos movimientos que agitan el conjunto del que forma parte». La noción de servicio público es un excelente ejemplo de ello y para evidenciarlo se requiere escudriñar en un pasado muy actual.

2 S. Díez Sastre (2018), La formación de conceptos en el Derecho público. Un estudio de metodología académica: definición, funciones y criterios de formación de los conceptos jurídicos, Madrid: Marcial Pons, pág. 29.

3 Ibid.: 31 .

4 F. Velasco Caballero (2020), Administraciones públicas y Derechos administrativos, Madrid: Marcial Pons, pág. 41.

5 S. Cassese y L. Torchia (2014), Diritto amministrativo. Una conversazione, Bologna: Il Mulino, pág. 96. S. Cassese, Derecho administrativo: historia y futuro, Sevilla: Global Law Press Editorial Derecho Global, págs. 459-460.

6 J. Caillosse (1982), «Sur les enjeux idéologiques et politiques du droit administratif», Revue Administrative, 208, págs. 361-368 (pág. 365). Traducción libre del autor, al igual que todas las que se contienen en este trabajo, a menos que se siga lo contrario del título de la obra (por tratarse de una traducción editorial). 
Las ideas de génesis y genealogía hacen referencia al principio de algo, a sus antecedentes más o menos remotos. En cierto sentido, son sinónimos de origen y, por ello, se prefirió este término, pues engloba ambas ideas. La primera, más próxima al sentido común, mientras que la segunda es más precisa y productiva cuando se trabaja con nociones que inciden en las prácticas discursivas constitutivas de la juridicidad estatal ${ }^{7}$. En efecto, mientras la génesis ayuda a explorar una noción en las coordenadas de la imagen lineal del tiempo ${ }^{8}$, una genealogía permite iniciar un recorrido desde el presente hacia momentos particulares del pasado que aún están —-manifiesta o latentemente- en la actualidad ${ }^{9}$, es decir, las ruinas actuales del pasado ${ }^{10}$.

Si bien noción y concepto pueden usarse como sinónimos, se opta por la primera expresión por cuatro razones: primero, pues «noción» alude a un conocimiento incipiente, no lo suficientemente decantado. De este modo, se evidencia que se trata de un trabajo de derecho comparado que aborda dos derechos administrativos como derechos extranjeros ${ }^{11}$, de manera que se acepta la existencia de algo que se ignora y que resistirá siempre así ${ }^{12}$. Segundo, porque se sirve de la distinción de Koubi entre noción — política — y concepto - jurídico- ${ }^{13}$, pero dado que esos dos aspectos resultan indisociables del «servicio público", no puede sino optarse por la idea de noción, tanto para no reducir la riqueza del fenómeno estudiado como para, precisamente, poder explicarlo. Se puede afirmar que no se trata solo de conceptualizar y estructurar la lectura del derecho según un riguroso aparato categorial; sino, a la inversa, de localizar la presencia de un determinado tiempo histórico (con sus contradicciones y conflictos) en las conceptualizaciones y los sistemas dogmáticos o doctrinales

M. Foucault (1969), L’archéologie du savoir, Paris: Gallimard; M. Foucault (1971), L’ordre $d u$ discours, Paris: Gallimard; M. Foucault (1990), "La vérité et les formes juridiques», Chimères. Revue des schizoanalyses, 10, págs. 8-28; J. de Gliniasty (2017), «La force du discours en droit administratif», Revue interdisciplinaire d'études juridiques, 79, págs. 77-92; G. Koubi y W. Tamzini (2020), Discours administratifs, droit(s) et transformations sociales, Paris: IRJS Éditions.

8 R. Koselleck (2016), historia/Historia, 3a edición, Madrid: Trotta. Una crítica a esa representación en: J. Fontana (2018), L’ofici d'historiador, Barcelona: Arcàdia, págs. 31-54; Velasco Caballero (2020: 39-41) y J. Bell (2020), The Anatomy of Administrative Law, Oxford: Hart, págs. 25-64.

9 J. Fernández Sebastián y J. Tajadura Tejada (2021), Tiempos de la Historia, tiempos del Derecho, Madrid: Marcial Pons, págs. 17-21.

10 G. Agamben (2019), Arqueologia de la Política, Barcelona: Arcàdia, págs. 17-19.

11 M.-C. Ponthoreau (2015), «Droits étrangers et droit comparé: des champs scientifiques autonomes?», Revue internationale de droit comparé, 67, págs. 299-315.

12 F. Quezada Rodríguez (2020), «Una aproximación crítica a la comparación de derechos administrativos», Revista de Derecho Público: Teoría y Método, 1, págs. 7-28.

13 G. Koubi (2014), «L'idéologie du service public», en VV. AA., Le service public (págs. 4153), Paris: Dalloz. 
en apariencia tan abstractos ${ }^{14}$. Tercero, porque fue la expresión con la cual se tradujo la categoría francesa a principios del siglo XX. En efecto, tanto Posada ${ }^{15}$ como Jordana de Pozas ${ }^{16}$ la utilizan. Finalmente, porque permite hacer referencia a la distinción francesa entre teoría del servicio público, escuela del servicio público y la noción de servicio público ${ }^{17}$.

La comparación jurídica no es algo dado, sino que se construye; por ello siempre requiere la honestidad intelectual de explicitar al máximo sus supuestos, tal como se intentó previamente. Todo lo cual permite, así, explorar críticamente un discurso doctrinal bastante asentado en la discusión hispanohablante, según el cual esta noción tendría su origen en el derecho francés, el cual sería su centro de elaboración técnico jurídica y de problematización intelectual ${ }^{18}$, mientras que el caso español sería uno de «recepción», dándose a entender que alguien habría ido a los escaparates galos, visto una interesante "mercancía» jurídica bellamente expuesta, la hubiese adquirido, empacado y enviado a España ${ }^{19}$. Como si el derecho hubiese viajado y aterrizado en tierras hispanas.

Por último, se debe señalar que esta reflexión se pretende elaborar desde el pensamiento crítico, el comparatismo crítico y el intento de una aproximación crítica al derecho administrativo ${ }^{20}$. Una de las ventajas de emprender un camino

14 D. Losurdo (2019), El marxismo occidental, Cómo nació, cómo murió y cómo pude resucitar, Madrid: Editorial Trotta, pág. 183; R. Koselleck (2012), Historias de conceptos, Estudios sobre semántica y pragmática del lenguaje político y social, Madrid: Editorial Trotta, págs. 45-48; J. Derrida (2018), Fuerza de ley. El fundamento mistico de la autoridad, Madrid: Tecnos, pág. 32.

15 A. Posada (1923), Tratado de Derecho Administrativo, según las teorías filosóficas y la legislación positiva, 2a edición, Madrid: Librería General de Victoriano Suárez, pág. 267.

16 L. Jordana de Pozas (1924), Derecho Administrativo, Madrid: Librería General de V. Suárez, pág. 137.

17 F. Melleray (2001), «École de Bordeaux, école du service public et école duguiste. Proposition de distinction», Revue du Droit Public, 6, págs. 1887-1905.

18 J. Tornos (2016), «El concepto de servicio público a la luz del derecho comunitario», Revista de Administración Pública, 200, págs. 193-211; C. Chinchilla María (1997), «Servicio público: ¿crisis o renovación?», en E. Malaret (dir.), Régimen jurídico de los servicios públicos (págs. 59-98), Madrid: Consejo General del Poder Judicial.

19 Analogía de la «tesis IKEA» en: G. Frankenberg (2018), Comparative Constitutional Studies, Between Magic and Deceit, Cheltenham: Edward Elgar Publishing, págs. 111-136.

20 Subyace a esta reflexión la propuesta teórica de Jacques Caillosse en (2008), La constitución imaginaire de l'administration, Paris: PUF; J. Caillosse (2017), L'État du droit administratif, Paris: LGDJ. Como también el administrativismo crítico de J.-J. Gleizal (1980), Le droit politique de l'État. Essai sur la production historique du droit administratif, Paris: PUF. También la teoría del campo jurídico de Pierre Bourdieu en (1986), «La force du droit [Élements pour une sociologie du champ juridique]", Actes de la recherche en sciences sociales, 64, págs. 3-19. La cual luego fue aplicada al derecho administrativo en J. Chevallier 
así es que temas aparentemente agotados o sobre los cuales se haya escrito tanto, tal como el que se aborda en este trabajo, pueden resultar siempre ricos en posibilidades de reflexión nuevas. Para estos efectos, este trabajo se organiza en tres tiempos: (i) primero, se reconstruye la elaboración de la noción francesa de servicio público; luego, en un segundo momento, se desarrollan (ii) los vínculos entre dicho proceso con la construcción propiamente española; finalmente (iii) se entregan algunas conclusiones que se siguen de lo anterior y que podrían dar lugar a investigaciones futuras.

\section{LA FORMACIÓN DE LA NOCIÓN FRANCESA DE SERVICIO PÚBLICO}

Como señala Chevallier, el service public es una noción «saturada de significaciones múltiples», que se superponen, se entrecruzan, reenvían unas a las otras, y entre las cuales existe un deslizamiento constante ${ }^{21}$. Se trata, según el mismo autor, en primer lugar, de una verdadera entidad social que engloba diversas actividades y estructuras bajo la dependencia de colectividades públicas, constitutivas de la "esfera pública», que presentan un conjunto de especificidades que impiden toda asimilación a las empresas privadas. Luego, explica que también es una noción jurídica que implica la aplicación de reglas jurídicas específicas y derogatorias del derecho común, las cuales condensan y resumen aquello que constituye el particularismo del derecho administrativo francés. Finalmente, señala, es también un operador ideológico, que esculpe el mito de un Estado generoso, finalizado hacia el bienestar de todos. Sería un "principio axiológico» que se enmarca y guía la gestión pública, una finalidad a la cual se deben referir los gobernantes y funcionarios, y de la cual depende la legitimidad de sus actuaciones ${ }^{22}$. Por ello, se trata de una noción compleja, en la cual se mezclan de manera indiscernible, indisociable e indisoluble lo real y el mito, unido por el derecho ${ }^{23}$. Esta noción aparece así como la pieza maestra de la construcción estatal francesa ${ }^{24}$, un elemento clave de su pacto social repu-

(1989), "Changement politique et droit administratif», en VV. AA., Les usages sociaux $d u$ droit (págs. 293-326), Paris: PUF; J. Chevallier (2002), «Doctrine et science juridique», Droit et Société, 50, págs. 103-119. También a la historia del derecho en J.-L. Halpérin (2012), «La détermination du champ juridique à la lumière de travaux récents d'histoire du droit», Droit et Société, 81, págs. 405-423.

21 J. Chevallier (2015), Le service public, 10ª edición actualizada, Paris: PUF, pág. 4.

22 Ibid.

23 Ibid.: 5.

24 Ibid. 
blicano ${ }^{25}$. Un modelo original que es el resultado de circunstancias históricas particulares ${ }^{26}$.

¿Cómo se llega a este punto? ¿Cómo esta noción adquiere un significado tan denso? Para responder estas preguntas se requiere explorar su génesis, como el momento preciso en el cual se incorpora en los trabajos de los administrativistas y las connotaciones que va adquiriendo, es decir, su genealogía. Aunque son dos caminos distintos de análisis, no son indisociables: la génesis marca la noción en un sentido relevante que no desaparece en el quehacer propio de los administrativistas. La primera dejó «ruinas» que perduran hasta hoy.

\section{LA GÉNESIS Y GENEALOGÍA DE UNA POLISÉMICA NOCIÓN PROPIAMENTE FRANCESA}

El servicio público ha sido erigido en Francia a la altura de un verdadero mito, es decir, en una de sus imágenes fundadoras, que sirve de apoyo y soporte a la construcción de la identidad colectiva; por ello es usual que se le predique la expresión "a la francesa». Por cierto, en toda sociedad es posible encontrar un conjunto de actividades consideradas de interés común que deberían estar, en razón de ello, a cargo de la colectividad: el servicio público evoca dicha esfera, necesaria para la existencia misma de lo social ${ }^{27}$. Se trataría de una noción con raíces antiguas y que aparece inherente a la organización de las sociedades modernas. En cierto sentido, sería posible decir que, históricamente, a la vez que nacen las civilizaciones, nace el derecho administrativo — materialmente- como servicio público ${ }^{28}$.

El sustantivo adjetivado service public tiene un Francia una larga historia y se vincula a nociones vecinas como utilité publique ${ }^{29}$ e intérêt généraß ${ }^{30}$. En efecto, su origen se remonta al latín, de las palabras servitium, que designaba la condición de esclavo; y publicus, que refería a aquello que concierne al pueblo, a la colectividad en su conjunto ${ }^{31}$. Desde un estudio histórico documental, Mestre concluye

25 G. J. Guglielmi, G. Koubi y M. Long (2016), Droit du service public, 4a edición, Paris: LGDJ, pág. 29.

26 P. Esplugas-Labatut (2018), Le service public, 4a edición, Paris: Dalloz, págs. 1-8.

27 J. Chevallier (2019), Science administrative, Paris: PUF, págs. 216-217.

28 J. C. Scott (2019), Homo Domesticus. Une histoire profonde des premiers États, Paris: La Découverte; A. Badiou (2018), Petrograd, Shanghai, Les deux révolutions du XXe siècle, Paris: La fabrique éditions, págs. 18-19; J. Chevallier (2019: 49-50).

29 J. Broch (2014), "L'utilité publique dans l'ancienne France», Cahiers poitevins d'Histoire du droit, 5-6, págs. 179-209.

30 J. Broch (2017), «L'intérêt général avant 1789. Regard historique sur une notion capitale du droit public français», Revue histoire de droit, 95, págs. 59-86.

31 J.-L. Mestre (2004), «L'emploi de l'expression «service public» sous l'Ancienne Régime», en G. Guglielmi, Histoire et Service public (págs. 20-38), Paris: PUF, págs. 20-21. 
que «es evidente que la expresión 'servicio público' formaba parte, sobre todo en la segunda mitad del siglo XVIII, del lenguaje político-administrativo. Se utilizó tanto en textos solemnes emanados del poder real como en escritos que fueron precursores de la Revolución» ${ }^{32}$. También adquiere connotaciones ideológicas bajo el Antiguo Régimen, pues «da la impresión que aquellos que gobiernan, que aquellos que administran, incluso aquellos que detentan un monopolio de explotación, son los servidores de la colectividad, y no unos 'déspotas' que abusan de sus poderes por satisfacer sus propios deseos o intereses» ${ }^{33}$. Posteriormente, en los tiempos revolucionarios pareciera haberse mantenido, más o menos, en los mismos términos, pero, esta vez, como predicado de autoridades dotadas de una nueva legitimación ${ }^{34}$. Incluso será positivada en el texto constitucional de 1791, en su art. $12^{35}$.

La Comuna de París de 1871 será un hito decisivo, pues ahí nace un nuevo discurso. En efecto, la noción será marcada con nuevas connotaciones debido al uso que le dan sectores sociales, hasta ese momento marginados de la política institucionalizada, y los círculos intelectuales incidentes. A juicio de Koubi, los "preceptos e ideas concebidos, compuestos, afirmados, desarrollados y a veces aplicados durante los meses de marzo, abril y mayo de 1871 marcaron subrepticiamente, pero profundamente, la concepción del servicio público en Francia: en cierto modo, podrían considerarse como la raíz de la concepción laica y republicana del servicio público, que aún persiste hoy en día ${ }^{36}$. Sería el momento en el cual, de la aspiración a la construcción de una República social, se sigue la relación necesaria entre el servicio público y la satisfacción de las necesidades de los sectores desfavorecidos bajo el supuesto de la igualdad ${ }^{37}$. Por ello, por ejemplo, la educación pública, gratuita e integral deviene en un servicio público de primer orden ${ }^{38}$.

Como puede verse, concurren discursos con pretensiones relacionadas con el ejercicio del poder administrativo, sea tanto para legitimarlo (desde arriba) como para desafiarlo o repensarlo (desde abajo). La ideología administrativa ${ }^{39}$ ya había elaborado discursos de difusión, con consistencia y fuerza operativa. Sin embargo, aún no se integraban en las construcciones de los juristas ${ }^{40}$, lo cual acontecerá con posterioridad.

\section{Ibid.: 29.}

33 Ibid.: 34; J.-L. Mestre (1985), Introduction historique au droit administratiffrançais, Paris: PUF, págs. 270-274.

34 Mestre (2004: 29-34).

35 «La garde du roi ne pourra être commandée ni requise pour aucun autre service public».

36 G. Koubi (2004), «Révolution et Service public pendant la Commune de Paris de 1871», en G. Guglielmi, Histoire et Service public (págs. 83-140), Paris: PUF, págs. 84-85.

37 Ibid.: 95.

38 Ibid:: 133.

39 Chevallier (2019: 543-590).

40 Gleizal (1980: 51-52). 
El Estado liberal propio de las transformaciones revolucionarias, aunque heredero de la burocracia regia ${ }^{41}$, comenzará a dar paso a la formación de un Estado social cada vez más interventor en todas las esferas de la sociedad. La industrialización, el surgimiento de la clase obrera, el sindicalismo y el explosivo crecimiento urbano implicarán diversas exigencias al Estado, que se involucrará de forma más activa en la vida social, adquiriendo notas particulares tanto a nivel central como local, destacando en esto último el denominado socialismo municipal. Estos cambios tendrán un correlato en el sentido común de aquel entonces, pues desde las diversas expresiones del liberalismo de origen revolucionario se dará lugar, sin abandonar sus elementos básicos en lo político y económico, a una doctrina solidarista cuya base será compartida por las fuerzas políticas protagónicas de la III República ${ }^{42}$. La burocracia estatal crecerá constantemente y, por lo mismo, el derecho que se refiere a aquella.

El fenómeno antes descrito tendrá un importante impacto en el derecho administrativo, pues el derecho positivo (como texto y en su operatividad real) sobrepasará los marcos conceptuales hasta ahí desarrollados. Dado el dualismo jurídico característico del derecho francés, que se manifiesta en una marcada distinción entre derecho público y derecho privado, proyectada tanto a nivel jurisdiccional (un juez administrativo que aplica derecho público y un juge judiciaire que aplica derecho privado ${ }^{43}$ como pedagógico (en la distinción de las agregaciones de los profesores de derecho ${ }^{44}$, se planteará un importante problema teórico y práctico: ¿cuál es el campo de aplicación de las reglas del derecho administrativo y la competencia del juez administrativo? Lo cual, a su vez, implicaba el problema de delimitar el campo disciplinar de aquellos que se dedicaban a esta nueva área del saber. En otros términos, ante la superación por la realidad del Estado gendarme del liberalismo clásico, surgen dos problemas capitales, uno de índole teórico-político y otro estrictamente práctico: (i) ¿cuál es el fundamento de este Estado y su derecho?, es decir, ¿cuál era el fundamento del derecho público? y (ii) ¿qué es el derecho administrativo?, es decir, ¿qué es ese derecho que debe aplicar el juez administrativo?

Todo será respondido por la misma noción: el servicio público, idea que funda el Estado, que determina el derecho que aplica el juez administrativo y que delimita su competencia. A una expresión con existencia previa se le asignará un significado propio en la comunidad de administrativistas. En este proceso se pueden identificar tres hitos: (i) las construcciones teóricas de Duguit y Hauriou;

41 A. de Toqueville (1856), L’Ancien Régime et la Révolution, Paris: Michel Lévy Frères, Libraires-Éditeurs, págs. 49-63.

42 G. J. Guglielmi, G. Koubi y M. Long (2016: 51-57).

43 J. Chevallier (1970), L'élaboration historique du principe de séparation de la juridiction administrative et de l'administration active, Paris: LGDJ; J. Krynen (2018), Le théâtre juridique. Une histoire de la construction du droit, Mesnil-sur-l'Estrée: Gallimard, pág. 341-370.

44 D. Truchet (2014), Le droit public, 3ª edición actualizada, Paris: PUF, págs. 21-31. 
(ii) la inauguración de la escuela del servicio público por Jèze; y (iii) la primera edición del libro Les grands arrêts de la jurisprudence administrative de 1956.

La nueva realidad social y su incidencia en el campo jurídico dará lugar a empresas teóricas de gran envergadura, cuyos principales exponentes serán Duguit y Hauriou. Si pudieran sintetizarse los puntos medulares del proyecto intelectual del primero, se podrían señalar dos grandes temas: (i) limitar la intervención estatal en expansión mediante la construcción de un concepto de derecho ajeno al mero derecho positivo (su sociológica idea de derecho objetivo) ${ }^{45}$ y (ii), en el contexto del desarrollo de los nacionalismos pre y concomitantes a la Primera Guerra Mundial, desarrollar una teoría del (nuevo) Estado propiamente francesa, que no resultase tributaria de las abstracciones germanas ${ }^{46}$.

Para este republicano de derecha moderada ${ }^{47}$, tal como se sigue del título de uno de sus famosos estudios, el derecho público se había transformado: «[...] se ha producido una transformación económica formidable durante la segunda mitad del siglo XIX, incompatible con el sistema jurídico rígido y metafísico que había construido la Revolución» ${ }^{48}$. Así, luego de exponer las importantes transformaciones económicas y sociales que se vivían en su época, señala que:

[...] la noción de servicio público viene a sustituir a la de soberanía. El Estado ya no es un poder soberano que manda; es un grupo de individuos con poder que deben utilizarlo para crear y gestionar los servicios públicos. La noción de servicio público se convierte en la noción fundamental del derecho público moderno. Los hechos lo demuestran ${ }^{49}$.

45 J.-M. Blanquer y M. Milet (2015), L'invention de l'État, Léon Duguit, Maurice Hauriou et la naissance du droit public moderne, Paris: Odile Jacob, págs. 121-122. Asimismo lo explica el propio autor en la introducción de su obra Les transformations du droit public. Ahí afirma que la teoría de la autolimitación estatal, que denomina subjetivista, opone al derecho subjetivo del Estado, el derecho subjetivo del individuo, y funda sobre ello la limitación de la soberanía y los deberes que se le impone al Estado. A su juicio «c'est un système métaphysique, pusqu'il repose essentiellement sur le concept de droit subjectif, qui est certainement d'ordre métaphysique. C'est enfin u système impérialiste ou régalien, puisqu'il implique que les gouvernats exercent touhours la puissance commandante, l'imperium de la nation organisée en État».

46 J.-M. Blanquer y M. Milet (2015: 242-243). Lo propiamente francés de esta construcción, visto como un derecho extranjero, desde un autor alemán en D. Grimm (2016), «Une lecture allemande de Léon Duguit», Revue du droit public, 1, págs. 185-194. También en S. Cassese (2014: 360).

47 La faceta política de Léon Duguit, documentada en la prensa de la época, en J.-M. Blanquer y M. Milet (2015: 231-238).

48 L. Duguit (1913), Les transformations du droit public, Paris: Librairie Armand Colin, pág. XVI.

49 Ibid.: XIX. 
Como puede verse, su noción de servicio público es indisociable de su teoría del Estado; por ello su desarrollo se encuentra en Las transformaciones del Derecho Público y en su Tratado de Derecho Constitucional. Como el mismo autor señala, dicha noción no es nueva, lo novedoso será el rol que cumplirá en el campo jurídico del derecho público ${ }^{50} \mathrm{y}$, en especial, el derecho administrativo. Así, luego de exponer el origen de las teorías alemanas de la autolimitación ${ }^{51}$, su recepción en Francia por Eismen ${ }^{52}$, señala que la doctrina gala ya habría percibido la insuficiencia explicativa para la nueva realidad social, citando para ello los dos publicistas, a su juicio, más representativos de su época: Berthélemy y Hauriou ${ }^{53}$, de quienes señala que si bien identifican el problema y la solución, no llegarían a asentar una base sólida para una nueva construcción teórica, la cual «es fundamentalmente la noción de servicio público" "54. Así, el Estado deja de ser un poder que manda, una soberanía, y deviene en una cooperación de servicios públicos organizados y controlados por los gobernantes 55 .

Según esta teoría, el Estado será limitado por un derecho objetivo, es decir, algo que le es exterior y superior, el cual nace de las exigencias de la "conciencia social» y de la «solidaridad social ${ }^{56}$. El rol del Estado será, por intermedio de los servicios públicos, la realización de esta última ${ }^{57}$. Por ello señala Touzeil-Divina que lo que construye Duguit no es una teoría del servicio público, sino más bien una teoría del Estado a través del servicio público ${ }^{58}$. Así, en este razonamiento se funda la definición duguista o concepción objetiva de servicio público: «Es toda actividad cuya prestación debe ser asegurada, regulada y controlada por los gobernantes, porque resulta indispensable para la realización y el desarrollo de la interdependencia social, y es de tal naturaleza que solo puede serlo plenamente mediante la intervención del poder gobernante» ${ }^{59}$. Esta noción es objetiva, puesto que el servicio público no se crea, sino que se constata ${ }^{60}$, se trataría de una realidad social que, en términos de la episteme positivista, podría denominarse meta-

$50 \quad$ Ibid: $33-34$.

51 Véase el capítulo I en ibid.

52 Ibid.: 36-37.

53 Ibid: $38-40$.

54 Ibid: 40 .

55 Ibid: $47-51$.

56 Esplugas-Labatut (2018: 13).

57 Ibid.

58 M. Touzeil-Divina (2019), Dix mythes du droit public, Paris: LGDJ, págs. 160-161; F. Melleray (2009), «Léon Duguit. L’État détrôné», en N. Hakim y F. Melleray (coords.), Le renouveau de la doctrine française. Les grands auteurs de la pensée juridique au tournant du XXe siècle (págs. 215-262), Paris: Dalloz.

59 L. Duguit (1928), Traité de droit constitutionnel, $3^{\text {a }}$ edición, tomo II, Paris: Ancienne Librairie Fontemoing \& Cie, Éditeurs. E. de Boccard, Successeur, pág. 61.

60 Esplugas-Labatut (2018: 14). 
jurídica. A pesar de sus diversas divergencias, normalmente atestiguadas en todos los manuales de derecho administrativo francés, esta concepción objetiva será compartida por Hauriou.

Aunque Duguit ya había avanzado en la traducción de su teoría en nociones doctrinales, incorporando jurisprudencia del Consejo de Estado de su época ${ }^{61}$, ese paso decisivo, según Rivero, había sido dado antes por Hauriou en su Gestion administrative. Étude théorique de droit administratif de 1899. Ahí refunda las bases teóricas y dogmáticas del derecho administrativo francés, superando la doctrina que distinguía actos de autoridad y actos de gestión, aquilatada en la obra Laferrière (Traité de la juridiction administrative et des recours contentieux, 1887). De este modo, el inventor del tema jurídico del servicio público sería Hauriou, pues es el primero en convertirla en una noción mayor de derecho administrativo fuera de la dicotomía clásica en ese momento ${ }^{62}$.

Sea como sea, lo relevante es que los pilares teóricos duguistas permitirán a Jèze, sucesor en la escuela de Burdeos, emprender una nueva sistematización del derecho administrativo, en la cual la noción de servicio público cumplirá el mismo rol central y estructurante. En efecto, lo que caracteriza el paso doctrinal de Jèze es que constituye esta noción en la «piedra angular» del derecho administrativo francés ${ }^{63}$. Propone, siguiendo el realismo de su maestro, definir el servicio público no por lo que debería ser, sino tal cual es. Así, constata que efectivamente los servicios públicos no existen por sí, sino que conciernen a una voluntad, la de los gobernantes, en sentido amplio, y, en especial, a la del legislador. De este modo, afirmará: «[...] son únicamente, exclusivamente servicios públicos, las necesidades de interés general que los gobernantes de un país determinado, en un momento dado, en una época determinada, han decidido satisfacer mediante el procedimiento de servicio público. La intención de los gobernantes es lo único que hay que tener en cuenta» ${ }^{64}$. De este modo, propondrá una noción subjetiva, según la cual la cualificación de servicio público depende de la decisión de las autoridades competentes sobre la existencia de una necesidad de interés general ${ }^{65}$.

Más allá de las divergencias o silencios entre los autores clásicos, de este desarrollo se aquilatará, desde una legitimación nueva fundada en una teoría del estado propia, un cierto invariable del servicio público, dado por tres elemen-

61 Con todo, según Touzeil-Divina (2019: 159-160), la síntesis doctrinal del servicio público habría tenido íntegramente su germen en construcción de Duguit en lo que denomina «la ecuación duguista».

62 J. Rivero (1956), «Hauriou et l'avènement de la notion de service public», en VV. AA., L'évolution du droit public. Études en l'honneur d'Achille Mestre (págs. 461-471), Paris: Sirey.

63 Melleray (2001: 1888-1889).

64 G. Jèze (1925), «Les éléments essentiels du service public - A quoi reconnait-on un service public proprement dit ? Les retraites ouvrières et paysannes constituent-elle un service public?», Revue du droit public, págs. 503-537 (pág. 510).

65 Esplugas-Labatut (2018: 16). 
tos definitorios: (i) el elemento orgánico, constituido por la persona pública que dirige el servicio (los gobernantes); (ii) el elemento funcional, que no puede ser otro que el interés general, el cual no está constituido por la simple suma de intereses privados, ni una negociación entre aquellos, sino como una noción que los trasciende, y, finalmente (iii) el elemento material, constituido por las reglas de derecho aplicables al servicio público, las cuales se caracterizan por su carácter derogatorio del derecho privado o exorbitante del derecho común, es decir, es el autónomo derecho administrativo. Un aspecto relevante de dicho régimen serán los tres grandes principios que aporta Rolland, también conocidas como las leyes de Rolland o, simplemente, las leyes del servicio público: la continuidad, la igualdad y la mutabilidad. Todo lo anterior convierte a la noción en «la piedra angular» del derecho administrativo francés, que estaría consagrada en la famosa decisión Blanco del Tribunal de Conflictos.

\section{LA MITIFICACIÓN DE LA DECISIÓN BLANCO DE 1873.}

Pues bien, de lo desarrollado hasta acá, a cualquier lector perspicaz le resultará problemática esa referencia: ¿cómo una sentencia de 1873 puede consagrar un desarrollo teórico y doctrinal elaborado décadas después? En realidad, la decisión Blanco, aunque zanjó un conflicto competencial sobre la responsabilidad patrimonial de la Administración en 1873, devino en el "hito fundador» del derecho administrativo en un proceso que culmina en 1956. Por ello, en cierto sentido, aquella decisión «nace» en la segunda mitad del siglo XX y deviene en lo que es, en un sentido importante, gracias al aporte de Rolland. En efecto, en la época de su dictación o es soslayada — en la obra de Ducrocq y Laferrière- o simplemente relegada a un papel menor - como acontece en las obras de Duguit y Hauriou- ${ }^{66}$. Lo cual se explicaría por su carácter no innovador en la jurisprudencia de la época ${ }^{67}$, lugar común entre los historiadores del derecho administrativo $^{68}$; tanto es así que para Brunet bien podría ser reemplazada por otras ${ }^{69}$. Por cierto, esto no es una novedad en el medio hispanohablante, como hace varias décadas aclaró Parejo ${ }^{70}$.

66 T. Perroud, J. Caillosse, J. Chevallier y D. Lochak (dirs.) (2019), Les grandes arrêts politiques de la jurisprudence administrative, Paris: LGDJ, págs. 43-48.

67 Se debe matizar lo anterior, pues, junto a otras decisiones, habría sido relevante en materia de responsabilidad. Así se explica en H. Belrhali (2017), Responsabilité administrative, Paris: LGDJ, pág. 39.

68 F. Burdeau (1995), Histoire du droit administratif, Paris: PUF, págs. 131-134 y 233-235.

69 Tales como los arrêts Rothschild, Gloxin o Dekeister. Así lo señala en: P. Brunet (2014), "Doctrines juridictionnelles et doctrines méta-conceptuelles du service public», en VV. AA, Le service public (págs. 21-39), Paris: Dalloz, pág. 22.

70 L. Parejo (1984), El concepto del derecho administrativo, Caracas: Editorial Jurídica Venezolana, págs. 94-97. 
El rol de "piedra angular» ni siquiera le fue atribuida por la escuela del servicio público ni por los seguidores de Duguit ${ }^{71}$, sino que se debe a Waline y su visión sobre el derecho administrativo francés. Tal como explica Bigot, en su Manuel élémentaire de droit administratif de 1946, dicho jurista atribuirá, por primera vez, a la decisión Blanco ser «la piedra angular de todo el derecho administrativo $»^{72}$. Con todo, lo decisivo ocurrirá una década después, cuando incorpora esa visión en el influyente libro Les grands arrêts de la jurisprudence administrative, el famoso GAJA, obra elaborada bajo su iniciativa y la de René Cassin, vicepresidente del Consejo de Estado, cuya primera edición aparece en 1956.

Esta obra es decisiva en la cultura administrativa gala; a través de ella se construyen los discursos doctrinales dominantes y son transmitidos en la enseñanza del derecho administrativo. Bien se podría afirmar que, en el seno de las facultades de derecho, se le constituyó en un referente de estudio similar al que es el Código Civil para los civilistas. Tanto es así que cuando se discute doctrinalmente, se enseña o se alega ante la jurisdicción administrativa, basta hacer referencia a una decisión ahí incorporada para dar por entendido implícitamente cierto criterio técnico-jurídico. De esta manera, se consagró en la práctica la idea de Waline de que el derecho administrativo francés es una construcción jurisprudencial (cuando en realidad es un coro a dos voces, como señala Rivero, entre la doctrina universitaria y el Consejo de Estado ${ }^{73}$ ) y el rol decisivo en ello de Blanco ${ }^{74}$.

Pues bien, a la famosa decisión del Tribunal de Conflictos del 8 de febrero de 1873 se le atribuye tradicionalmente ser la "piedra angular» puesto que consagraría tres cuestiones claves: (i) determina la competencia del juez administrativo; (ii) aquilata el contenido mismo del derecho administrativo; y (iii) afirma el principio de vínculo entre la competencia y el fondo. El criterio para determinar todo lo anterior sería la noción de servicio público ${ }^{75}$. Pues bien, ¿`cómo una operación de este tipo fue posible? Como bien se sigue de lo explicado hasta acá, la historicidad que se va plasmando en la noción es de tal densidad que lo constituye en una

71 Perroud et al. (2019: 49-50).

72 Ibid.: 51.

73 J. Rivero (1955), «Jurisprudence et doctrine dans l'élaboration du droit administratif», Conseil d'État. Études et documents (págs. 27-36), Paris: Imprimerie Nationale, pág. 36.

74 Esta exposición es una síntesis del debate sobre la importancia del GAJA en la cultura jurídica francesa que tuvo la Association Française pour la recherche en Droit Administratif el ańo 2006, al conmemorar el 50a aniversario de la publicación de dicha obra. Las contribuciones se encuentran en el dosier especial que publicó la Revue Française de Droit Administratif, 2, 2007. Sobre cómo operó, respecto a este libro, el «coro a dos voces» que señala Rivero, véase especialmente P. Cossalter (2015), «Les Grands arrêts de la jurisprudence administrative», en J. Caillosse y O. Renaudie, Le Conseil d'État et l'Université,Paris: Dalloz, págs. 163-177. En especial, respecto al rol del Consejo de Estado, J. Chevallier (2007), «Le Conseil d'État, au coeur de l'État», Pouvoirs, 123, págs. 5-17.

75 M. Long, P. Weil, G. Braibant, P. Devolvé y B. Genevois (2015), Les grands arrêts de la jurisprudence administrative, 20ª edición, Paris: Dalloz, págs. 1-7. 
especie de "concepto vehículo" de lo que acontece en la conflictividad social y lo traduce al lenguaje de los administrativistas ${ }^{76}$.

Por otro lado, es importante destacar que este rol asignado a la noción de servicio público en Blanco por el GAJA nació matizado por la realidad misma, ya incorporada en el diálogo doctrina-Consejo de Estado. Es decir, el significado que se le atribuyó se hizo paralelamente a un proceso similar que aconteció con otra decisión clave del Tribunal de Conflictos: Société commerciale de l'Ouest africain $^{77}$, popularizado como arrêt Bac d'Eloka. Resulta necesaria esta precisión para comprender posteriormente la particularidad del proceso espańol de construcción de la noción. En efecto, aquella decisión del 22 de enero de 1921, según lo que se le atribuirá en el $G A J A$, será el origen de los «services publics industriels et commerciaux ${ }^{78}$, esto es, de la idea que un particular podría gestionar un servicio público bajo las reglas de una empresa privada ${ }^{79}$. Asimismo, es relevante mencionar el arrêt del Consejo de Estado del 13 de mayo de 1938, Caisse primaire "Aide et Protection", pues ahí se reconoce expresamente la gestión de un servicio público a cargo de personas privadas. Es decir, se disocia, respecto del servicio público, su comprensión como institución, como órgano administrativo, y el servicio público como misión, como función. Se trata de una genuina innovación teórica y doctrinal, pues ahora la noción abarca, además del aparataje burocrático directamente estatal, también la actividad de un privado que presta un servicio según las reglas de una empresa privada, como las de un particular a cargo de un servicio público sin ningún tipo de vínculo contractual con el Estado ${ }^{80}$.

Aquella operación discursivo-ideológica fue posible gracias al decisivo aporte doctrinal de Rolland. En efecto, será él quien resuelva el gran dilema de aplicar un mismo derecho (administrativo) a fenómenos sociales tan distintos. Su propuesta será identificar que en todos aquellos sería posible predicar las mismas «leyes», las «leyes del servicio público» ${ }^{81}$. Así, no solo se convierte en el «salvador del servicio

76 Ch. Bosvieux-Onyekwlu (2019), «Revenir sur une légende en sociologie: l'arrêt Blanco et le mythe de la «naissance» du droit administratif français», Droit et Société, 101, págs. 159-178 (págs. 160-162). También en Ch. Bosvieux-Onyekwlu (2020), Croire en l'État. Une genèse de l'idée de service public en France (1873-1940), Paris: Éditions du croquant, pág. 23.

77 A. S. Mescherlakoff (1988), «L'arrêt du Bac d'Eloka. Légende et réalité d'une gestión privée de la puissance publique», Revue du Droit Public, 4, págs. 1059-1081.

78 Por cierto, dicho arrêt no menciona la categoría de «service public à caractère industriel et commercial», dicha construcción acontecerá una década después por dos autores, Pierre Laroque y Jean Delvolvé, la cual será coronada por su inclusión en el GAJA de 1956 (Perroud et al., 2019: 114-130).

79 Long et al., 2015: 207-215.

80 Ibid.: 294-299.

81 M. Meyer (2016), "Relire le Précis de droit administratif de Louis Rollanad», Revue Méditerranéenne de Droit Public, IV, págs. 40-52; L. Bézie (2006), «Louis Rolland: 
público» ${ }^{82}$, sino que permite que el GAJA atribuya a Blanco el rol decisivo antes explicado y que le permite nacer, efectivamente, en 1956.

La lectura conjunta de la interpretación que se le asigna tradicionalmente a estas tres decisiones (la ecuación Blanco-Bac d'Eloka-Caisse primaire) abre innumerables interrogantes, lo cual ha significado una gran cantidad de trabajo a los administrativistas, y de cuyas discusiones surgirá el debate, entre otros, sobre la "crisis del servicio público»" ${ }^{83}$. En ese contexto aparecerá luego un influyente artículo de Chapus, publicado en la Revue du Droit Public en 1968, el cual planteará que, si bien el servicio público seguiría siendo el criterio medular del derecho administrativo, sería la puissance publique la que determinaría la competencia del juez $\operatorname{administrativo~}^{84}$. Este relevante trabajo, esqueleto teórico de su obra posterior, será antesala de un relevante pronunciamiento del Consejo Constitucional que constitucionaliza un núcleo de competencia del juez administrativo ${ }^{85}$.

Todo lo expuesto antes permite afirmar que la saturación de significados que se cruzan bajo la noción de servicio público va desde una teoría del Estado, que lo dotaría de una nueva legitimación, a la resolución del problema de la delimitación del derecho que debe aplicar el juez administrativo y su respectiva competencia. Se teoriza, construye y aplica un régimen jurídico para un Estado social compatible con el liberalismo. Este complejo cruce es lo que caracteriza la noción de servicio público «a la francesa». Este proceso ha sido sintetizado por Caillosse, quien plantea que la doctrina francesa del servicio público sería el resultado de:

[...] una muy vieja tradición nacional que — por buenas razones- puede hacerse remontar a los famosos juristas del Antiguo Régimen. Ella vuelve visible los vínculos orgánicos entre dos procesos: la elaboración y la gestión de categorías jurídicas, por un lado; la construcción y la reproducción del Estado, por otro. El trabajo efectuado en torno al servicio público por los grandes teóricos del derecho y del Estado a partir de fines del siglo XIX es uno de los episodios más edificantes de esta larga historia cruzada por los usos sociales del derecho y la formalización jurídica de la experiencia estatal frances ${ }^{86}$.

théoricien oublié du service public», Revue du droit public, 4, págs. 847-878; F. Melleray (2007), "Retour sur les lois de Rolland», en VV. AA, Le droit administratif: permanences et convergences. Mélanges en l'honneur de Jean-François Lachaume (págs. 709-722), Paris: Dalloz.

82 M. Touzeil-Divina (2016), «Louis Rolland, Le Mediterraneen d'Alger, promoteur et sauveteur du service public», Revue Méditerranéenne de Droit Public, IV, págs. 17-32.

83 J.-L. de Corail (1954), La crise de la notion juridique de service public en droit administratiffrançais, Paris: LGDJ.

84 R. Chapus (1999), «Le service public et la puissance publique», en L'administration et son juge (págs. 37-75), Paris: PUF.

85 Long et al. (2015: 588-597).

86 Caillosse (2008: 46). 
Así, utilizando expresiones del mismo autor, la noción de servicio público sería un emblema de la identidad francesa ${ }^{87}$, de un pacto republicano ${ }^{88}$, mediado por el derecho administrativo, que fue capaz de traducir en la técnica jurídica discursos subyacentes (es decir, sociales, permitiendo el uso social del derecho ${ }^{89}$ ), constituyéndose en un punto de encuentro y disputa de la sociedad francesa ${ }^{90}$. Por cierto, estos mismos textos (tanto los arrêts como las opiniones de los clásicos) siguen siendo polémicos, como verdaderos campos de batallas semánticas, en el que se expresan las transformaciones sociales recientes, tanto por los discursos provenientes de las fuerzas homogeneizantes de la globalización neoliberal como por la impronta de la europeización jurídica ${ }^{91}$. Sin embargo, desarrollar aquello escapa a los objetivos de este trabajo y lo ya dicho permite evidenciar lo relevante en comparación con la creación española.

\section{UNA CREATIVA «RECEPCIÓN» EN EL DERECHO ESPAÑOL}

En estudios de derecho extranjero y de derecho comparado es usual que se catalogue el derecho administrativo francés como «exportador ${ }^{92}$ y el derecho administrativo espańol como «importador» ${ }^{93}$. Afirmaciones normalmente matizadas, evidenciando ciertas influencias extranjeras del primero e influencias en el extranjero

87 Ibid.: 50.

88 Ibid.

89 D. Lochak (1989), "Les usages du savoir juridique», en VV. AA., Les usages sociaux du droit (págs. 327-330), Paris: PUF; F. Audre y J.-L. Halpérin (2013), La culture juridique française. Entre mythes et réalités. XIXe-XXe siècles, Paris: CNRS Éditions.

90 Para solo dar un ejemplo, no resulta extraño que organizaciones sindicales ligadas a la izquierda radical elaboren discursos sobre la relevancia política de los servicios públicos y se planteen su defensa; como tampoco que representantes de los grandes intereses económicos planten discursos sobre cómo «modernizar» aquellos. Es decir, la noción (que es jurídica y político-social) seguiría siendo un campo de batalla por monopolizar o hegemonizar su significado.

91 Dichos fenómenos son distintos y con su propia complejidad. J. Chevallier (2017), L'État post-moderne, Paris: LGDJ, págs. 67-68; Caillosse (2008: 27-75; 2017: 49-73); C. Blumann (2007), "Quelques variations sur le thème du service public en Droit de l'Union Européenne», en VV. AA., Le droit administratif : permanences et convergences. Mélanges en l'honneur de Jean-François Lachaume (págs. 45-69), Paris: Dalloz.

L. Neville Brown y J. Bell (1998), French administrative law, Oxford: Clarendon Press, págs. 268-287; M.Touzeil-Divina (2018), «Du service public systematisant: à propos de la circulation de(s) doctrine(s) du service public en Mediterranée (influences \& confluences)», Revue Méditerranéenne de Droit Public, VIII, págs. 29-115.

93 A. Gallego (1999), "La influencia extranjera en el derecho administrativo español desde 1950 a hoy", Revista de Administración Pública, 150, págs. 75-114; A. Neyrat (2019), Le rapport du droit administratif national aux droits administratifs étrangers. Les cas de la France et de l'Espagne, Paris: L'Harmattan, pág. 149. 
del segundo (especialmente en Latinoamérica ${ }^{94}$ ). Sin embargo, estas referencias, si bien permiten iniciar una discusión, en tanto simplificaciones, pueden llevar a equívocos tanto intelectuales como históricos. En efecto, no es inusual leer a propósito del servicio público en Chile o Bolivia, solo por citar dos ejemplos, referencias a un origen francés y luego una reflexión con citas de autores españoles ${ }^{95}$. Incluso, en un contexto así, alguien podría aventurar que «la noción de servicio público nace de la doctrina y jurisprudencia francesa que, recibida en España, sigue siendo influyente en Latinoamérica por el permanente intercambio intelectual con este último país». Lo que podríamos llamar la tesis simplista de «España como puente». Lo mismo podría señalarse de los autores alemanes e italianos.

Caricaturas de ese tipo ocultan lo relevante, esto es, develar lo que el derecho administrativo nacional hace mediante la construcción de discursos que incorporan un derecho extranjero (equívoco intelectual); y ocultan hechos históricos importantes, como la amistad entre Posada y Letelier, quienes no solo se leían mutuamente, sino que se influían recíprocamente en sus investigaciones, como bien lo reconoce el primero en el prólogo de su obra sobre derecho administrativo $^{96}$, y luego en diversas citas de aquel ${ }^{97}$ (equívoco histórico). Incluso aceptando que España sea «un puente» para América Latina hacia Europa, en ningún caso ha sido unidireccional, a lo menos, en lo que concierne a la noción de servicio público $^{98}$.

Resulta innegable que los administrativistas españoles practican cierta erudición respecto al derecho del entorno europeo y de Estados Unidos ${ }^{99}$. Esta práctica, con antecedentes relativamente antiguos ${ }^{100}$, puede ser un impor-

94 D. López-Medina (2012), «The Latin American and Caribbean legal traditions, Repositioning Latin America and the Caribbean on the contemporary maps of comparative law», en M. Bussani y U. Mattei (eds.), The Cambridge Companion to Comparative Law (págs. 344-367), New York: Cambridge University Press.

95 J. A. Martínez (2018), Derecho Administrativo Boliviano, 3o edición, Santa Cruz de la Sierra: Imago Mundi, págs. 275-277; J. Bermúdez (2014), Derecho Administrativo General, $3^{\circ}$ edición, Santiago: Legalpublishing, págs. 295-307; L. Cordero (2015), Lecciones de Derecho Administrativo, 2a edición, Santiago: Thomson Reuters, pág. 470.

96 Posada (1923: XV -XIX). Lo llamaba «mi queridísimo colega» y «sabio publicista».

97 Así, por ejemplo, al construir su visión sistemática e interdisciplinaria del derecho administrativo (su visión «enciclopédica», como el mismo autor lo denomina), no solo cita a Letelier, sino también a Amunátegui, otro de los impulsores del derecho administrativo chileno (Posada, 1923: 20).

98 A. Posada (1896), «La fonction administrative de l'État», Revue du droit public, 5, págs. 289-302 (pág. 290).

99 Así, por ejemplo, Parejo (1984).

100 J. A. Santamaría (2013), «La ciencia del Derecho administrativo en España: una perspectiva histórica», en A. von Bogdandy y O. Mir, Ius Publicum Europaeum. El derecho administrativo en el espacio jurídico europeo (págs. 341-383), Valencia: Tirant Lo Blanch; A. Nieto (1983), «Apuntes para una historia de los autores del derecho administrativo general 
tante indicio sobre los rasgos de la identidad del derecho administrativo español ${ }^{101}$, es decir, podría tratarse de la expresión de las particularidades históricas de su realidad social. Pareciera ser que los juristas españoles están permanentemente leyendo las obras de los administrativistas de aquellos países que identifican como centros de producción intelectual ${ }^{102}$ y las incorporan en sus discusiones. Ello sería parte de lo propiamente español de su derecho administrativo: una lectura permanente, de siglos, del derecho extranjero, es decir, una creativa recepción-apropiación de categorías, teorías y textos jurídicos foráneos ${ }^{103}$. Un buen ejemplo del idiosincrático sincretismo del derecho administrativo español lo constituye, precisamente, la noción de servicio público. Pues la discusión sobre su alcance y efectos resulta inexplicable sin considerar las referencias francesas (entre otras), constituyendo, a la vez, una categoría jurídica muy particular.

\section{TERRENO FÉRTIL PARA LA RECEPCIÓN: UNA LARGA INFLUENCIA FRANCESA Y LA CONSTRUCCIÓN DE UNA NOCIÓN DE SERVICIO PÚBLICO EN POSADA}

Durante el siglo XIX autores pioneros del derecho administrativo mirarán con particular interés la doctrina francesa. Se trata de los denominados «afrancesados», tanto por su formación gala como, en ciertos casos, un pasado de apoyo a la ocupación francesa. Se trata de De Burgos, Oliván y Silvela ${ }^{104}$. Si bien todos ellos siguen con explícita admiración el desarrollo de la disciplina en Francia, su discurso doctrinal parece haber sido útil en una realidad propiamente española: una histórica relación conflictiva entre la capital y las provincias. Por ello, puede aventurarse la hipótesis que un derecho administrativo marcado por el centralismo habría sido de especial interés para los gobernantes de Madrid. Se habría tratado de construir «el centro» propio del Estado moderno $^{105}$. En efecto, la unidad administrativa y la centralización son temas

español», en 34 artículos seleccionados de la Revista de Administración Pública con ocasión de su centenario (págs. 17-67), Madrid: Instituto Nacional de la Administración Pública.

101 A. Neyrat (2019: 124).

102 En dicha afirmación lo relevante sería el verbo «identifica», pues normalmente no se estudia con la misma atención todo el entorno europeo; J. Varela (2020), Historia constitucional de España, Madrid: Marcial Pons, pág. 573.

103 Neyrat (2019: 143)

104 Ibid.: 125-129.

105 L. Medina Alcoz (2021), «Historia del Derecho Administrativo (I). Del Estado Liberal al Estado Autoritario", en J.-M. Rodríguez de Santiago, G. Doménech Pascual y L. Arroyo Jiménez, Tratado de Derecho Administrativo. Volumen I. Introducción. Fundamentos (págs. 95-228), Madrid: Marcial Pons, págs. 149-154. 
que cruzan la obra de Gómez de la Serna, Posada Herrera, Colmeiro, Oliván y Santamaría de Paredes ${ }^{106}$.

Este contexto será especialmente propicio para que la discusión desde la cual se construyó la noción francesa de servicio público se siguiera muy de cerca. No solo uno de sus protagonistas visitará el país, Duguit, sino que su obra será leída con gran interés y sus traducciones aparecerán con muy poco desfase desde su publicación. En dicho fenómeno serán claves tres nombres: Posada, Jardón y Dorado. El primero será el traductor, el segundo su contradictor y el tercero su seguidor ${ }^{107}$. Sin embargo, «es con Adolfo de Posada - a quien luego seguirían Royo (1927), Gascón (1928), Jordana (1924), García Oviedo (1927) y, definitivamente, Fernández de Velasco (1930) — con quien tiene traducción la doctrina francesa del servicio público, que luego la jurisprudencia recogerá aceptando en sus considerandos las definiciones teóricas ${ }^{108}$.

Por cierto, el sustantivo adjetivado «servicio público» también era una expresión que se utilizaba de forma previa, aunque, probablemente, con connotaciones similares a las existentes en los círculos del poder real en Francia. Ejemplo de ello pareciera ser Oliván, quien señalará que «el fundamento de la organización administrativa está en determinar el modo más feliz y eficaz de que se desempeñe bien el servicio público» ${ }^{109}$. Sin embargo, será Posada quien no solo introduzca la teoría del Estado de Duguit, sino que la desarrollará y problematizará con originalidad ${ }^{110}$, además de utilizarla como base para sistematizar y teorizar el derecho administrativo de su época. Su obra es de una riqueza sorprendente, de una erudición destacable y de un rigor intelectual sin precedentes en los autores consultados de ese tiempo; se trata de una concepción propiamente enciclopédica del derecho administrativo ${ }^{111}$. Incluso, aunque se le atribuye a Colmeiro el

106 A. Martín Descalzo (1952), Notas para una historia del derecho administrativo (España, Francia, Italia, Alemania), Valladolid: Ed. Miñón (págs. 14-29); F. Tomás y Valiente (2013), Manual de Historia del Derecho Español, $4^{\circ}$ edición, Madrid: Tecnos, págs. 591592; S. Martín-Retortillo (1997), Alejandro Oliván: Reflexiones sobre su vida y su obra, Madrid: Civitas, págs. 84-90.

107 T. R. Fernández (2010), «Léon Duguit en España y en Español», Revista de Administración Pública, 183, págs. 31-49.

108 J. L. Villar Palasí (1977), Apuntes de Derecho Administrativo, Parte General, tomo I, Madrid: Artigrafía, pág. 100.

109 Martin Descalzo (1952: 20). En esa misma página, el entusiasmo lo lleva a avanzar una tesis muy difícilmente justificable, señala: «No es absolutamente preciso invocar los nombres de Jèze, Duguit, Hauriou, Bonnard, Bielsa, para exponer la noción del servicio público como elemento fundamental de una concepción del derecho administrativo, ya que en 1843 [lo habría hecho Oliván]».

110 En efecto, todo su derecho administrativo es, en rigor, una pieza dentro de una obra mayor que teorizaba el Estado y la sociedad; F. Laporta (1974), Adolfo Posada: Politica y sociología en la crisis del liberalismo español, Madrid: Cuadernos para el Diálogo, págs. 115-139.

111 Varela (2020: 566). 
hito de dotar de sentido unificador a la disciplina en Espańa, haberlo alcanzado por primera vez habría que atribuírselo a Posada ${ }^{112}$. Por cierto, al igual que otros autores de la época, cita autores alemanes e italianos, así como, particularmente, los franceses de su época.

Por no desarrollar su trabajo intelectual en un contexto de dualismo jurisdiccional, la noción de servicio público no jugará un papel relevante en la construcción del contencioso administrativo. Así, en la segunda edición de su Tratado de Derecho Administrativo según las teorías filosóficas y la legislación positiva de 1923, se lee que el fundamento del servicio público:

[...] $1^{\circ}$, se basa en la noción del fin del Estado, al servicio de los fines que justifican su existencia; $2^{\circ}$, no se puede definir concretamente de un modo, por decirlo así, objetivo, determinado y definitivo, porque tal concreción depende de la noción dominante y propulsora del fin del Estado, de la misión que a éste se atribuya, o sea de las necesidades que se estime preciso someter a su acción eficaz, y, en su virtud, el sistema y el régimen de los servicios públicos, en otros términos, las materias objeto de ellos, y el criterio —-método - para desempeñarlos — prestarlos_ dependerán, en cada Estado y momento, de lo que la opinión pública, la conciencia colectiva, consideren como exigencias finales necesarias, y del modo como se entienda que la exigencias quedarán mejor satisfechas ${ }^{113}$.

En un segundo momento de su argumento, para unir la teoría del Estado con una definición del derecho administrativo y una noción de un servicio público, señala:

El Estado, en efecto, pone su poder jurídico — la ley, la acción ejecutiva, la gestión administrativa, las garantías jurisdiccionales - al servicio de la necesidad sentida, ya sea fomentando la acción privada —individual o social—, ya suscitando el medio adecuado o contribuyendo a procurarlo y a conservarlo, merced a estímulos económicos, a privilegios de explotación, a exacciones de cargas, a la remoción de obstáculos, al apoyo de la ley, y, por fin, realizando las oportunas operaciones legislativas, económicas y de gestión administrativa, para procurar, conservar y perfeccionar el medio idóneo con que el Estado mismo, u otra institución, entidad, empresa, a su nombre, atienda a la satisfacción de la necesidad determinante del servicio exigido ${ }^{114}$.

112 Alejandro Nieto (1983: 59), al incluirlo dentro de los primeros administrativistas que sistematizan la disciplina según lo que denomina el «método jurídico», dirá sobre su obra «Ha quedado [...] como uno de esos gigantescos edificios que no llegan siquiera a ser inaugurados». Para José Esteve es «la figura más relevante del Derecho público en España en el periodo de entreguerras». J. Esteve Pardo (2019), El pensamiento antiparlamentario y la formación del Derecho público en Europa, Madrid: Marcial Pons, pág. 106.

113 Posada (1923: 272).

114 Ibid.: 275. 
De esto se sigue que, entonces, el servicio público puede realizarse tanto con exclusión de los particulares como concurriendo con ellos en la satisfacción de la necesidad de interés general. Lo relevante será que se sigue «el procedimiento de servicio público» ${ }^{115}$, lo que en este contexto significa la aplicación del régimen jurídico del derecho administrativo. Lo anterior le permitirá avanzar otra noción, la que denomina "realista y jurídica», según la cual «los servicios públicos los constituyen las organizaciones adecuadas de personal técnico capaz de aplicar, con la máxima eficacia y economía; al fin del servicio, los medios de que al efecto dispone, empleando los procedimientos administrativos del caso» ${ }^{116}$. Termina su análisis aplicando lo desarrollado a problemas de la época como la descentralización y el sindicalismo de los funcionarios ${ }^{117}$.

Un año después de la segunda edición del tratado de Posada, Jordana de Pozas publica su derecho administrativo. Se trata de unas «oposiciones al cuerpo de secretarios de ayuntamiento (primera categoría), contestaciones al cuestionario del Ejercicio teórico» ${ }^{118}$. En ella hará una correcta exposición de este tema. A su juicio, «de cuantas nociones fundamentales debe fijar el Derecho administrativo ninguna iguala en importancia a la del servicio público» ${ }^{119}$ y añade que «suele existir sobre su concepto mayor conformidad de la que se observa en otros ya analizados, pero las definiciones varían según el punto de vista de que se parta» ${ }^{120}$, aunque matiza que «trátase, siempre, de una noción poco precisa, caracterizada por su generalidad, por la indeterminación de los sujetos y por ser de mala o imposible satisfacción mediante la actividad de los particulares» ${ }^{121}$. Sin embargo, por lo que acontecerá con posterioridad, es interesante destacar que le atribuye como caracteres jurídicos más importantes: un territorio, un personal y un material, medios financieros, en algunos casos, personalidad jurídica y, como consecuencia, un patrimonio. Luego añade que «[n]i la coacción, por la cual el uso del servicio se hace obligatorio; ni el monopolio, por el que se prohíbe a los particu-

115 Ibid.: 276

116 Ibid:: 285.

117 Ibid:: 286-292.

118 Resulta curioso que Eduardo García de Enterría la haya calificado como «la primera obra, sin duda, de su tiempo", que "supone un verdadero "salto epistemológico» por relación a los Manuales y obras generales entonces existentes». Si bien puede entenderse que pronuncie aquellas loas, pues las escribe en un obituario en honor a Jordana de Pozas, lo que resulta más llamativo es que ni siquiera mencione la obra de Posada. En efecto, si se revisa la obra, podrá comprobarse que es sustantivamente menor su valor sistémico y teórico en comparación al tratado de Posada. Aquellas expresiones sobre el temprano libro de Jordana de Pozas en E. García de Enterría (1984), «In memoriam», Revista de Administración Pública, 103, págs. 5-14 (pág. 9).

119 Jordana de Pozas (1924: 137).

120 Ibid.

121 Ibid.: 138. 
lares la prestación de servicios iguales o análogos, constituyen caracteres del servicio público, por cuanto hay servicios públicos voluntarios y sin monopolio» ${ }^{122}$.

En suma, desde la construcción de Posada hasta la primera elaboración de Jordana de Pozas puede verse que se entiende la noción de servicio público en términos originales por las características de la obra del primero y no difiriendo respecto al lugar que se le otorga a la labor privada.

\section{LA NOCIÓN DE SERVICIO PÚBLICO «EN SENTIDO ESTRICTO»COMO UNA CREACIÓN PROPIAMENTE ESPAÑOLA}

Es importante la exposición anterior, pues posteriormente, en la obra madura de Jordana de Pozas y un artículo clave de Villar Palasí, se atribuirá a la noción de servicio público un significado extraño a los desarrollos previos, y muy distinta a la construida en Francia. Se puede afirmar que se trata de una creación propiamente hispana, la cual se realiza en dos momentos: primero, mediante la introducción de la categoría de «actividad de fomento» y, luego, la denominada «actividad industrial».

En 1949 Jordana de Pozas publica su famoso artículo «Ensayo de una teoría del fomento en el derecho administrativo», en el cual define el servicio público como «una modalidad de la acción administrativa que consiste en satisfacer la necesidad pública de que se trate de una manera directa por órganos de la propia Administración creados al efecto y con exclusión o concurrencia de los particulares» ${ }^{123}$. Luego hace un brevísimo excurso sobre lo que denomina "una abundante floración de nuevos servicios públicos» ${ }^{124}$, señalando que las necesidades que atienden «han sido históricamente satisfechas por procedimientos de derecho privado y pueden volver a serlo si cambian las circunstancias» ${ }^{125}$. Así, pasa después a reducir el ámbito de actividad estatal atribuible a la noción de servicio público mediante la incorporación de la «acción de fomento», «una vía media entre la inhibición y el intervencionismo del Estado, que pretende conciliar la libertad con el bien común mediante la influencia indirecta sobre la voluntad del individuo para que quiera lo que conviene para la satisfacción de la necesidad pública de que se trate» ${ }^{126}$. Aquella la define como "la acción de la Administración encaminada a proteger o promover aquellas actividades, establecimientos, riquezas debidos a los particulares y que satisfacen necesidades públicas o se estiman de

122 Ibid: 140.

123 L. Jordana de Pozas (1949), «Ensayo de una teoría del fomento en el derecho administrativo", Revista de Estudios Políticos, 48, págs. 41-54 (pág. 44).

124 Ibid.: 45.

125 Ibid: $45-46$.

126 Ibid.: 46. 
utilidad general, sin usar la coacción ni crear servicios públicos» ${ }^{127}$. Como puede verse, la actividad administrativa, que antes estaría sistematizada bajo la noción de servicio público desarrollado conjuntamente con los particulares, ahora es escindida para comenzar una teorización nueva. Por cierto, la expresión «fomento» tiene en España un antecedente antiguo en la famosa «Instrucción para gobierno de los Subdelegados de Fomento» de De Burgos, pero sin que se le atribuya, en esa época, el discurso doctrinal que se está exponiendo ${ }^{128}$.

Si bien en el decisivo artículo de Jordana de Pozas no se exponen los fundamentos de su proyecto intelectual, es razonable suponer que se encuentran en su crítica al intervencionismo estatal y las ideas de reforma social contenida en un artículo que debe leerse junto al anterior y que se publica dos años después, titulado «El problema de los fines de la actividad administrativa». Esa crítica lo lleva a formular el siguiente principio:

[...] la Administración sólo debe intervenir cuando una necesidad general lo exige y el corolario de que entonces debe hacerlo en la medida en que compruebe la insuficiencia de la iniciativa individual o social, no sustituyéndose por entero a ella sino cuando sea extremadamente conveniente ${ }^{129}$.

La consecuencia doctrinal de aquello será, entonces, la siguiente:

[...] hace tiempo que vengo estudiando lo referente a los modos de la actividad administrativa ordenados, en una escala progresiva que, partiendo de la simple emanación de normas, pasa por la policía y el fomento hasta llegar al servicio público monopolizado. Los medios empleados deben ser aquellos que consigan el fin perseguido en el momento adecuado, pero con el grado mínimo de coacción ${ }^{130}$.

Como puede verse, la definición que ofrece de servicio público, considerando el acervo teórico-jurídico de ese momento, resulta contradictoria con la incorporación de la nueva categoría. La resolución de este inconveniente se debe al trabajo de Villar Palasí, en su primera formulación, en el artículo «La actividad industrial del Estado en el derecho administrativo». En dicho trabajo señala que «el proceso expansivo de lo público al enfrentarse con los esquemas lógicos clásicos muestra la inadecuación de éstos para servirles de instrumento y dar forma a las nuevas tareas

127 Ibid. Estas ideas tienen un antecedente, aunque aún sin la misma refinación conceptual: L. Jordana de Pozas (1943), «Algunas consideraciones sobre los servicios municipales de carácter económico", Revista de Estudios de la Vida Local, 9, págs. 333-338.

128 M. Arenilla (1996), La teoría de la administración en Javier de Burgos, Sevilla: Instituto Andaluz de Administración Pública, pág. 46.

129 L. Jordana de Pozas (1951), «El problema de los fines de la actividad administrativa», Revista de Administración Pública, 4, págs. 11-28 (pág. 26).

${ }^{130}$ L. Jordana de Pozas (1951: 27). 
estatales» ${ }^{131}$, para luego agregar que "por lo que hace a la estructura formal de la actividad administrativa, se venían tradicionalmente discriminando tres categorías de actuación: policía, fomento y servicio público» ${ }^{132}$. Si bien dicha afirmación está justificada con un pie de página en el cual cita a Tomás de Aquino, filósofo que, a su juicio, recuerda dicho esquema, resulta sorprendente que le atribuya el carácter de ser una tripartición «tradicional». En efecto, como se sigue de su exposición de la historia del derecho español en sus Apuntes de Derecho Administrativo, pareciera intentar elaborar una disciplina propiamente española, vinculada a una tradición nacional que sigue un desarrollo propio. Esto es, para su construcción la idea de «tradición» no solo tiene un sentido propio, sino que es de una relevancia particular. Por ello resulta curioso que la utilice respecto de una propuesta dogmática publicada un año antes. Sea cual sea el sentido que pretendió atribuirle al uso de la idea de tradición en ese momento, lo más interesante es la definición que luego dará de la noción de servicio público, pues, para distinguirla de las otras dos categorías, señala que se trata de «aquella actividad administrativa de prestación positiva, a través de un servicio técnico, regular y continuo, realizado para y frente al público por organización pública nomine propio o por delegación $»^{133}$. Luego, en un pie de página, señala que se trataría de un "servicio público en sentido restringido»" ${ }^{134}$. A esta idea se le ligará la noción de publicatio, mediante la cual «se atribuye a la Administración la titularidad de una determinada actividad cuyo ejercicio puede llevar a cabo por sí misma (a través de las formas directas de gestión) o encomendar a un tercero bajo cualquiera de las formas indirectas de gestión que, en esencia, son reconducibles a la técnica concesional» ${ }^{135}$. Lo anterior le lleva a afirmar que el servicio público tiene «una clara vocación al monopolio, que se presume [...], siendo este carácter en muchos casos inderogable» ${ }^{136}$. Según Albi, estas ideas se deben a la influencia autores italianos como Zanobini y Cameo, desde las cuales elaboraría un significado nuevo para la noción ${ }^{137}$.

Villar Palasí sustenta su propuesta en Hauriou, lo cual, para ese momento, como se expuso previamente, no solo resulta desfasado al desarrollo del derecho administrativo galo, sino que, de una manera descontextualizada, pues pareciera hacerle decir algo que, por su época y medio, no podría haber afirmado, lo cual es

131 J. L. Villar Palasí (1950), «La actividad industrial del Estado en el Derecho Administrativo», Revista de Administración Pública, 3, 1950, págs. 53-129 (pág. 58).

132 Ibid.

133 Ibid.: 69.

134 Ibid., en nota 9.

135 J. L. Villar Ezcurra (2000), «Los cauces de la intervención administrativa», en VV. AA. Don Luis Jordana de Pozas. Creador de la Ciencia Administrativa (págs. 283-307), Madrid: Laxes ediciones, pág. 300.

136 Villar Palasí (1950: 64).

137 F. Albi (1960), Tratado de los modos de gestión de las corporaciones locales, Madrid: Aguilar, págs. 142-143. 
más curioso si se consideran las referencias a Jèze. Con todo, no debe perderse de vista que este esfuerzo intelectual se realiza para introducir una nueva categoría, la «actividad industrial» ${ }^{138}$. En esta innovadora restricción de la noción de servicio público le secundará García de Enterría ${ }^{139}$. Debe tenerse presente que, si bien en esa época se había dictado el arrêt Bac d'Eloka, y la categoría de servicios públicos industriales y comerciales ya circulaba en el medio francés, no habían devenido en lo que son con posterioridad a la incorporación del primero como expresión de lo segundo en el $G A J A$.

En síntesis, esta noción "estricta» se debe a la creación original de Villar Palasí, luego asumida por García de Enterría, desde el ideario de Jordana de Pozas, académico al cual se unen los dos primeros tanto en la Universidad y el Consejo de Estado como en la Revista de Administración Pública ${ }^{140}$. Una de las consecuencias de este camino es que el servicio público es relegado de tal manera que, a diferencia de lo que acontece con los manuales de derecho administrativo francés, no aparecerá como una noción sistematizadora relevante en el Curso de Derecho Administrativo de García de Enterría ni en los Apuntes de Derecho Administrativo de Villar Palasí. Más allá del específico sentido que este último hubiere querido darle a su lectura en España de Hauriou, lo más llamativo de este proceso es que culmina con una noción de servicio público tan particular que resulta intraducible al francés. En efecto, como explica Malaret:

[...] un elemento tan característico como el que podríamos denominar requisito de la titularidad, que un sector de nuestra doctrina ha creído importar del Derecho francés, es totalmente desconocido en la legislación, jurisprudencia y doctrina de un país en el que recientemente incluso se ha acuñado la expresión servicio público a la francesa para referirse a lo que se considera un signo de identidad de un determinado modelo social. Lo que se pretende expresar con la noción de titularidad es tan ajeno al Derecho francés que no tiene incluso traducción posible ${ }^{141}$.

Por cierto, no todos los autores comparten la noción «estricta», lo cual ha dado lugar a discusiones dogmáticas, tanto respecto a su delimitación conceptual

138 Villar Palasí (1950: 61).

139 E. García de Enterría (1955), "La actividad industrial y mercantil de los municipios», Revista de Administración Pública, 17, págs. 87-138.

140 J. L. Villar Palasí (2000), "Don Luis Jordana de Pozas», en VV. AA. Don Luis Jordana de Pozas. Creador de la Ciencia Administrativa (págs. 13-14), Madrid: Laxes ediciones; E. García de Enterría (1999), «Para una historia interna de la RAP», Revista de Administración Pública, 150, págs. 611-621.

141 E. Malaret (1998), «Servicios públicos, funciones públicas, garantías de los derechos de los ciudadanos: perennidad de las necesidades, transformación del contexto», Revista de Administración Pública, 145, págs. 49-87 (pág. 56); E. Malaret (1997), «L'expérience espagnole», L’Actualité juridique - Droit administratif, págs. 136-142 (pág. 139). 
como al alcance del art. 128.2 de la Constitución espańola ${ }^{142}$. Lo cual, a su vez, también ha estado cruzado por los problemas teóricos, dogmáticos y políticos que imponen tanto la globalización neoliberal como la integración europea ${ }^{143}$. La literatura a este respecto también es abundante y la discusión particularmente rica. Por ello, solo puede dejarse enunciado, pues el curso que siguió el discurso de Jordana de Pozas y Villar Palasí requiere otro estudio.

\section{CONCLUSIONES}

De todo lo desarrollado es posible, por ahora, aventurar algunas hipótesis y plantear algunas preguntas:

1. Respecto a las hipótesis, pareciera ser que las diferencias de los casos estudiados podrían ser explicadas tanto por la historia de cada país como las diferencias del campo jurídico en ambas sociedades:

1.1. Mientras en Francia, en un contexto de liberalismo político y republicanismo, se construye una categoría expresiva de su realidad política y burocrática que sustenta un Estado social, en España las convulsiones políticas, crisis y una guerra civil seguida de una larga dictadura, con una Administración social posterior, explicarían que hiciera sentido la construcción de los destacados juristas de la $R A P$. En efecto, pareciera ser que elaboraron una categoría funcional al régimen jurídico de monopolios que se crearon en ciertas áreas, como consecuencia del programa de autarquismo económico de aquella época. Esta intuición se fundamenta en los ejemplos que utilizan en sus trabajos monográficos.

1.2. Mientras en Francia el Consejo de Estado y la Universidad, en tanto lugar propio de la doctrina, constituyeron un campo jurídico particular sin el cual resulta inexplicable su noción de servicio público, en Espańa, respecto a la doctrina de la noción estricta, el rol central lo tuvo la legislación estudiada, comentada, sistematizada y teorizada por los juristas vinculados a la $R A P$. Sin embargo, ese proceso tendría una lógica particular respecto de la incorporación del derecho extranjero en la discusión doctrinal ${ }^{144}$, puesto

142 A. Troncoso (1999), «Dogmática administrativa y derecho constitucional: el caso del servicio público», Revista Española de Derecho Constitucional, 57, págs. 87-164.

143 Tornos (2016); E. Malaret García (1997), «Servicios públicos y Unión Europea: los servicios públicos telefónicos en el marco de la liberalización de las telecomunicaciones, la reducción del ámbito del monopolio paso previo a su desaparición» (págs. 99-167), Madrid: Consejo General del Poder Judicial.

${ }^{144}$ En efecto, Alfredo Gallego Anabitarte señala respecto al derecho administrativo de la época franquista «con un sorprendente desarrollo de gran calidad, está lastrado por su propia historia oscilante, se construye sin propios fundamentos constitucionales y es muy dependiente de 
que pareciera ser que se utilizó como argumento de autoridad sin decir lo que con ello se hacía: crear una categoría completamente nueva ${ }^{145}$.

2. Lo anterior abre, a lo menos, las siguientes preguntas:

2.1. ¿Es tan cierta la originalidad de los autores galos expuestos en este trabajo? Si bien el mundo de aquella época no tenía la interconectividad de la cual se beneficia el quehacer académico actual, el caso de la amistad entre Posada y Letelier bien atestigua la existencia de círculos intelectuales de los cuales diversos medios se enriquecían ${ }^{146}$. Evidentemente, los franceses no fueron una excepción. La cuestión es por qué no se le da reconocimiento a lo foráneo en la construcción propia como sí lo hacen otros derechos. Una línea historiográfica se ha abierta recientemente en este sentido ${ }^{147}$ y que cuenta con un importante antecedente previo ${ }^{148}$.

2.2. ¿Por qué la omisión a la figura y obra de Posada en las construcciones de la generación $R A P$ ? Su obra es rica en posibilidades de reflexión y su propuesta enciclopédica del derecho administrativo se adelantó sorprendentemente a propuestas actuales sobre la necesaria interdisciplinariedad para comprender y explicar el fenómeno jurídico-administrativo. Su sistematización habría permitido construir una dogmática sofisticada, tal y como avanzó.

2.3. Pareciera ser que, en el medio español, «algo tuvo» la noción de servicio público que no pudo ser borrada y entonces fue subvertida, se le atribuyó un significado que bien habría justificado incluso otra denominación. Ello lleva a preguntarse no solo ¡cómo se realizó dicha operación doctrinal?, sino también ¿por qué?, ¿para qué?, ¿cómo opera dicho discurso en la realidad social actual? y, sobre todo, si la hipótesis del punto 1.1 resulta ser plausible y justificada, ¿qué sentido tiene mantener una construcción de ese tipo en un Estado social y democrático de derecho?

la doctrina y teoría jurídica extranjera», en (2002), Formación y enseñanza del derecho público en España (1769-2000). Un ensayo crítico, Madrid: Marcial Pons, pág. 287.

145 Sobre este fenómeno, M.-C. Ponthoreau (2009), «L'argument fondé sur la comparaison dans le raisonnement juridique», en P. Legrand (dir.), Comparer les droits, résolument (págs. 537-560), Paris: PUF.

146 No deja de ser llamativo en una de las citas que hace Posada (1923: XVII) a Letelier se mencione que las publicaciones madrileñas tardarían en arribar a Santiago de Chile en tan solo tres meses, y que se dé a entender que el medio de la Universidad de Chile participaba en los debates de los círculos intelectuales europeos de comienzos del siglo XX.

147 Audre, A.-S. Chambost y J.-L. Halpérin (2020), Histoires contemporaines du droit, Paris: Dalloz, págs. 18-24.

148 F. Melleray (dir.) (2007), L'argument de droit comparé en droit administratiffrançais, Brussels: Bruylant. 